\title{
An Ethnographic Study of Linguistic Landscapes at China-and-Vietnam Border
}

\author{
Jia Li ${ }^{1}$, Ying Yan ${ }^{1}$, Fuhuan $\mathrm{Hou}^{2} \&$ Juan Dong ${ }^{1}$ \\ ${ }^{1}$ School of Foreign Languages, College of English Department, Yunnan University, Kunming, China \\ ${ }^{2}$ Jianshui Experimental High School, Yunnan, China \\ Correspondence: Juan Dong, School of Foreign Languages, College of English Department, Yunnan University, \\ Kunming, China. E-mail: 18722808274@139.com
}

\author{
Received: October 26, 2019 Accepted: November 20, 2019 Online Published: December 15, 2019 \\ doi:10.5539/ijel.v10n1p127 URL: https://doi.org/10.5539/ijel.v10n1p127
}

\begin{abstract}
Along with China's Belt and Road Initiative, China is engaging itself with its neighboring countries and many border cities have been strategically positioned as trading nodes linking China to the outside world. This is particularly true with Hekou, a minority-centered border town between China and Vietnam where local minority languages, Chinese, Vietnamese and English are displayed at various spaces. Adopting a critical sociolinguistic ethnography (Heller, 2006; Li, 2017), this study focuses on the intersection of language practices and ideologies by examining the language use and language choices displayed both in public and private signs. Data were collected through linguistic signs displayed at Hekou and individual interviews with local people. Findings indicate that Chinese as China's official language enjoys the most visibility, and English, though considered as a lingua franca, only acquires symbolic value rather than being used for daily communication at the border town. In contrast, Vietnamese, as a newly emerged foreign language, is acquiring cultural and economic capitals for the local people' educational and employment opportunities. As a minority-centered border town, the visibility of minority languages on cultural events stands both for tourism boom and for border integrity. The study provides a new context for understanding multilingual practices and China's border language planning and management in the context of China's cooperation with Southeast Asian countries.
\end{abstract}

Keywords: linguistic landscapes, China, Vietnam, critical sociolinguistic ethnography

\section{Introduction}

The concept of linguistic landscapes was first put forward by Landry and Bourhis in 1997 and was defined as "The language of public road signs, advertising billboards, street name, place names, commercial shop signs, and public signs on government buildings combines to form the linguistic landscapes of a given territory, region, or urban agglomeration." (Shang \& Zhao, 2014a, p. 215). Linguistic landscapes not only study how different languages or varieties are used at a certain region but focus on the underlying meanings attached to the language signs (Shang \& Zhao, 2014b, p. 84). In the context of Belt and Road Initiative, Yunnan Province is playing a role of bridgehead in expanding cooperation with Southeast Asian countries. The demand for foreign language talents is urgent and how to efficiently realize the function of social service of language is a problem that needs to be addressed. There have been many studies regarding linguistic landscapes in big cities at home and abroad, while little is concerned with language use in rural and border regions where language and culture diversity is pervasive (Li, 2014). As one of the important ports bridging China and Vietnam, Hekou County is typical of multi-nationality and multilingual practices. Thus, on the basis of previous studies on linguistic landscapes, this paper takes Hekou County in Yunnan Province as an example to see how different languages are used in border regions.

Hekou Yao Autonomous County is located in the south of Yunnan Province and southeast of Honghe Autonomous Prefecture of Hani and Yi Nationality (Bai, 2015). There are Yao, Miao, Zhuang, Yi, Dai, Buyi and other 24 nationalities living at Hekou County (Hekou Year Book Editorial Department, 2016, pp. 513-515). Separated by Honghe River, Hekou stands on the opposite side of Lao Cai Province of Vietnam. The economic and cultural exchanges between Hekou and Lao Cai are very common. The improvement of Dian-Yue Railway, Kun-He Expressway and Honghe Shipping has made Hekou the most convenient port for linking Vietnam. It is 469 kilometers from Kunming city and 264 kilometers from Hanoi, the capital of Vietnam (see the figure below), making it the easiest passageway for going to Southeast Asian and South Asian countries for Southwestern China 
regions (Bai, 2015, p. 1).

Given its strategic positioning and the close geographical distance, Hekou has acquired its unique language practices in the context of China's and Vietnam's socioeconomic transformation. This study aims to explain the relationship between language and society, providing the relevant suggestions for making the border language policy and enhancing the border prosperity and border integrity.

\section{Literature Review}

\subsection{The Relationship Between China and Vietnam}

Since the establishment of China-Vietnam diplomatic relations in 1950, it has been 68 years that the two countries have been keeping friendly political interactions (Yang, 2017, p. 12). The close geographical location of the two countries provides great convenience for both sides to carry out foreign trade. After the normalization of relations and the founding of China-ASEAN Free Trade Area, the trade value between the two countries is growing rapidly (Yang, 2014, p. 2). Bordering China's Guangxi and Yunnan Province with a long borderline of 1450 kilometers, Vietnam is a key country for China's Belt and Road Initiative (Qin, 2017, p. 49). China's direct investment in Vietnam is in a rising trend in general, as is illustrated in the following figure (see Figure 1).

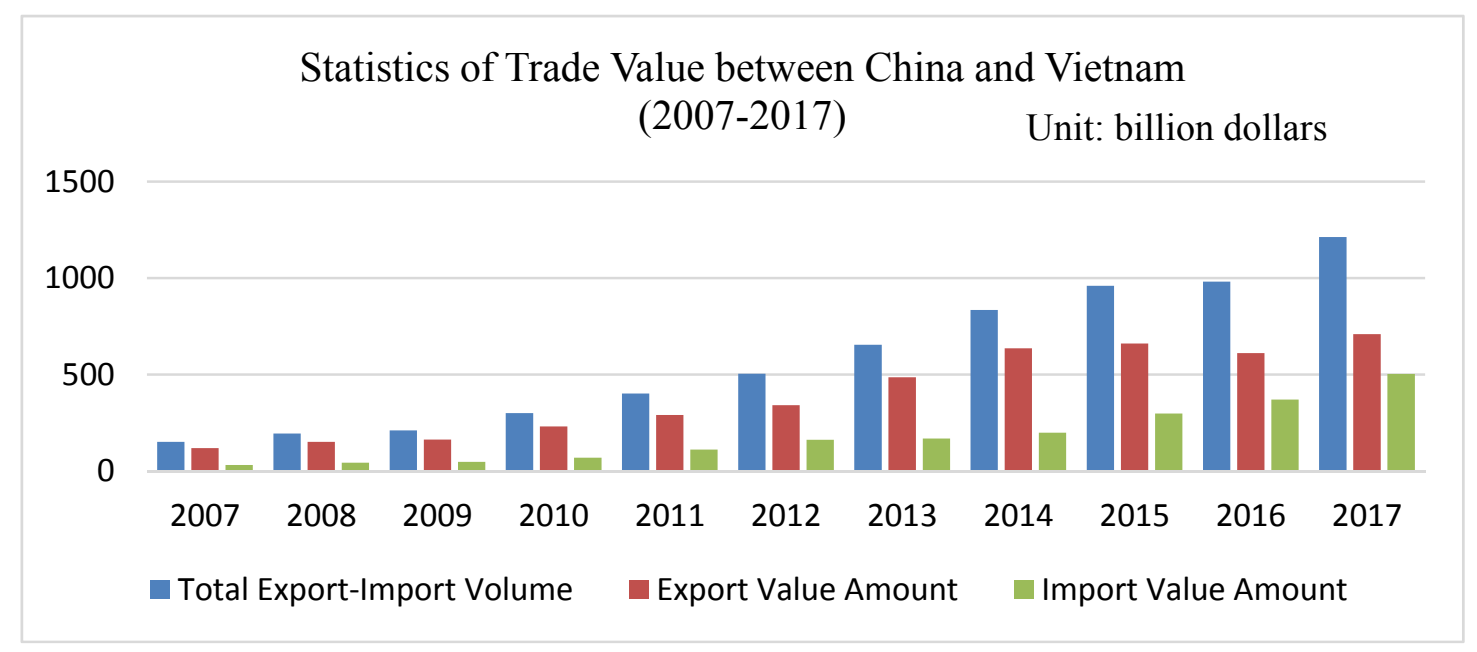

Figure 1. Trade value between China and Vietnam

Sources. Ministry of Commerce of People's Republic of China Department of Asian Affairs.

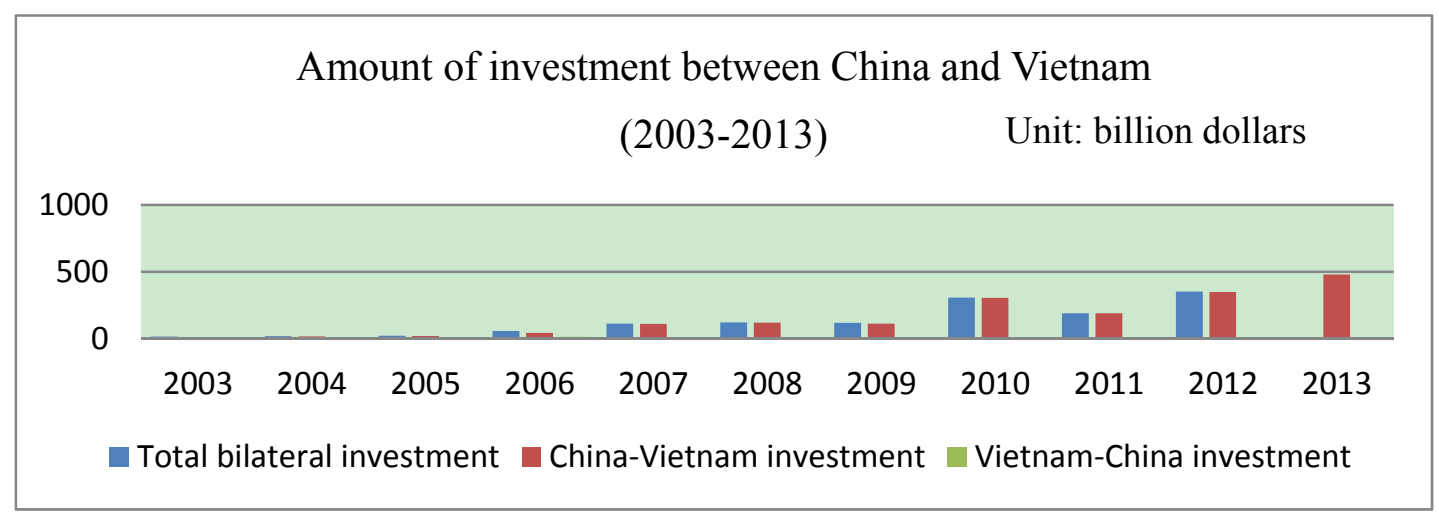

Figure 2. Net amount of investment between China and Vietnam

Sources. General Administration of Customs, P.R. China.

China's export commodities toward Vietnam are mechanical equipment, electrical machinery, steelwork, clothing, vehicle, mineral, fertilizer, etc. and China's import commodities from Vietnam include mineral, vegetable, rubber product, electrical machinery, cotton, fruit, furniture, wood ware, etc. Though the 
complementarity of commodities is not strong, trading scale between the two countries is expanding and trading relation is closely linked to each other. In Yunnan Province, there are 13 ports of first class, 7 of second class, 90 trade channels for border inhabitants and 103 areas of frontier trade, and for Guangxi Province, it has 17 ports of first class, 8 of second class and 25 areas of frontier trade (Ou \& He, 2016, pp. 123-124). Because of its geographical advantages in border areas as well as in coastal areas, Guangxi Province has been far exceeded in economic growth than Yunnan Province as was illustrated in Guangxi's export trade value to ASEAN countries. The geographical, resource, marketing, transportation and port advantage is beneficial in expanding cooperation between China and Vietnam.

\subsection{The Development of Vietnamese in China}

Vietnamese major was first offered by Beijing University in 1949 (Zeng \& Liu, 2005, p. 76). After that, University of International Business and Economics offered Vietnamese major in 1954, Beijing Foreign Studies University in 1961 and Guangdong University of Foreign Studies in 1970 (Zeng \& Liu, 2005, p. 76). For national strategy and regional development needs, Guangxi Minzu University offered Vietnamese major in 1964 and it was the only university to do this in Yunnan, Guangxi and Sichuan colleges and universities (Mo \& Yang, 2016, p. 72). After the normalization of relation between China and Vietnam, Yunnan Minzu University offered Vietnamese major in 1997 (Mo \& Yang, 2016, p. 72). Since the first China-ASEAN Exposition was hold successfully in Nanning in 2004, China has been working to keep a friendly relation with Southeast Asian countries, which led to other colleges and universities' offerings of Vietnamese major between 2005 and 2010. The cooperation within countries will increase the need for foreign language communication.

Now in the context of Belt and Road Initiative, the need for language elite in Southeast Asian languages is more urgent than ever before. As a country bordering on Yunnan and Guangxi Province, Vietnam is an important part in Belt and Road Initiative. Until 2014, China has been Vietnam's first business partner for 10 years and its greatest importing country (He \& Hao, 2014, p. 58). For that reason, Vietnamese has become a key language and is greatly needed in new economic cooperation era.

\subsection{Demographic Structures at Hekou}

As a minority-centered autonomous county, Hekou consists of Yao, Miao, Zhuang, Yi and other 31 minority groups, and the population of minorities is respectively 25136, 16128, 11908, 2014 (Hekou Year Book Editorial Department, 2016, pp. 513-515).

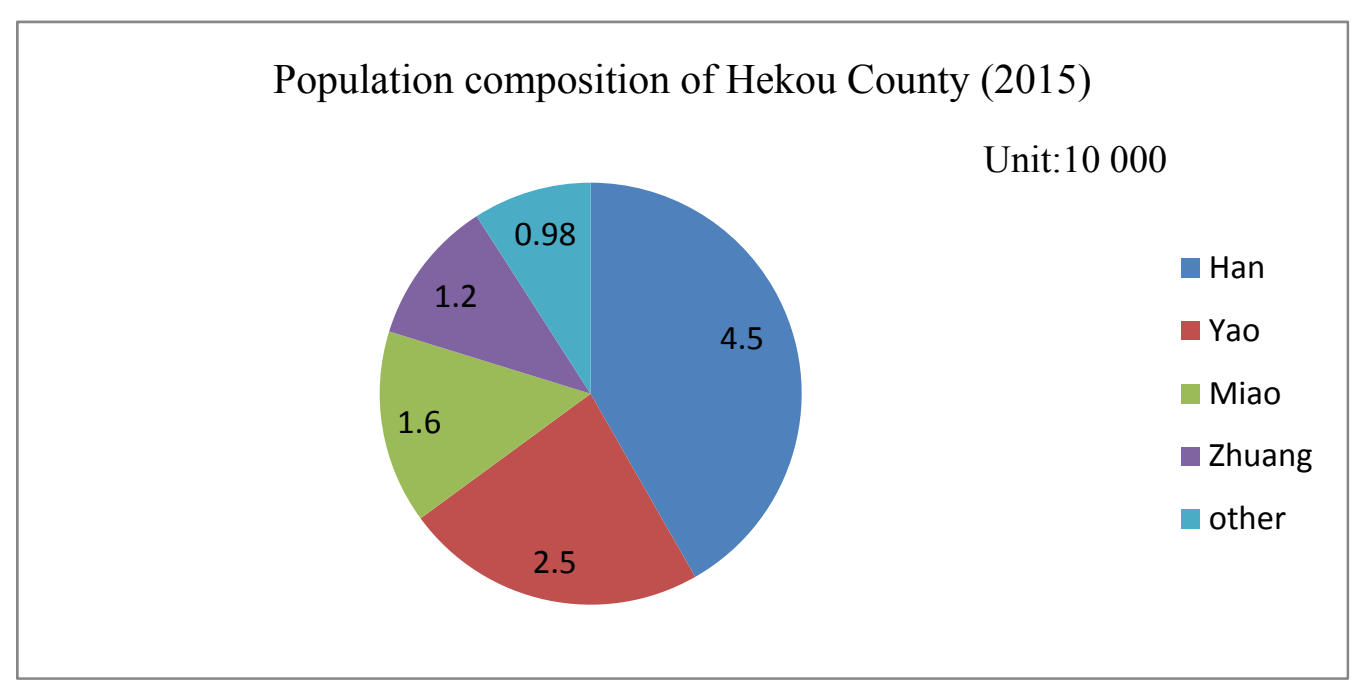

Figure 3. The population structure of Hekou autonomous county

Sources. Year Book of Honghe Prefecture, 2016.

As a county typical of multiple minority groups, there is a certain distribution pattern of Hekou's inhabitants. For Yao nationality, most of them live in Yaoshan town where the Panwang Temple is situated. Miao, Zhuang, Dai, Buyi and Yi nationality live in Qiaotou, which is the only autonomous country at Hekou. Qiaotou is the town most far away from Hekou County and it is typical of high altitudes and border lines. People's living standard 
there is lower than those in Nanxi and Yaoshan where altitude is lower and commercial crops such as banana and pineapple is plentiful.

Concerning the history of local residents at Hekou, the early settlers at Hekou are from Guangxi and Guangdong Province, who were once the members of Black Flag Army (Liu \& Li, 2009, p. 19). After the end of war, these soldiers stayed at Hekou, where it is easy to make a living by planting commercial crops like banana, pineapple and rubber tree (Liu \& Li, 2009, p. 20). After Hekou's liberation in 1950, educated youths from inland China came to Hekou for frontier development. At the same time, the once oppressed minorities living in mountainous areas went to town studying and working. After China's reform and opening-up and the restoration of border trade, a large number of translocal workers swarmed into Hekou from Zhejiang, Sichuan and Guizhou Province (Liu \& $\mathrm{Li}, 2009$, p. 24). The continuous influx of people made social groups at Hekou County more and more diversified since then.

While for foreign workers, they are mainly Vietnamese. According to the work report of Human Resources and Social Security Bureau of Hekou County in year 2017, there are about 6200 border workers from Vietnam and 2041 of them have applied for working residence in 2016. They carry on occupations like catering services, promotions specialist, jewelry sellers, timber processing, massager, car-washing, porter, and husbandry, etc. They take almost every observable profession at Hekou County. For registered population from other places of China and from Vietnam, there is no precise number counted. As a port, Hekou is a consumption-oriented and business-oriented county, where people come for doing business but do not treat it as one's life-long stay (Liu \& $\mathrm{Li}, 2009$, p. 21). Thus, flow rate of people is hard to collect and bring into administrative mechanism, which can be best illustrated by the fact that the Foreign Personnel Management Center was established just in August, 2017 (The introduction of the construction of Foreign Personnel Management Center at Hekou County, 2017, p. 2).

\subsection{Previous Studies on Linguistic Landscapes}

A bulk of literatures (Backhaus, 2005; Blommaert, 2013; Gorter, 2006; Huebner, 2006) on linguistic landscapes has been conducted on how different languages have been displayed in various social domains. The emerging study on language signs is closely associated with the global flow of capitals, people and languages from one place to another, one country to another. Given its convenience of collecting data on language choice and language forms, it seems that there has emerged a revitalization of multilingual diversity all over the world. However, what has been overlooked from celebrating the image of multilingual diversity is that few studies on linguistic landscapes have touched upon the power relation embedded in various language signs.

Adopting a critical approach to reveal the ideological power hidden in different language signs, a group of scholars have conducted empirical studies in various contexts of the globe. Huebner (2006) examines the language displayed in Bangkok, the capital city of Thailand, Southeast Asia. By examining the languages posted in both public and private spaces from 15 different neighborhoods, Huebner demonstrates the fact that English is a dominating language in Bangkok in that English is not only mostly widely circulated in the city landscapes but also shaping the usage of Thai language as well. Based on his description, the Thai, the official language of Thailand, has the tendency of mixing with English in many aspects like orthography, lexicology, phonology and syntax. In Tokyo, the capital city of Japan, Backhaus (2005) conducts his empirical study on how different languages have been promoted in different social domains by focusing on the power relation. Backhaus points out that linguistic landscapes displayed in official space mainly reinforce the existing power in Japan whereas those linguistic landscapes in nonofficial space indicate more options in using foreign languages targeting at different speakers.

In recent years, many scholars (Blommaert, 2013; Lou, 2016) are calling to adopt ethnography to understand the complexity of language use in relation to the wider socioeconomic process in conducting linguistic landscaping studies. Following a sociolinguistic ethnography conducted in Washington DC's China town, Lou (2016) reveals the complex relationships between language, place and time. In her study, Lou employs a variety of methodological tools to collect a variety of data including photographs, archival official documents, notes, video-recordings of community meeting and interviews with residents, community organizers and local workers. Such in-depth inquiry on how language is used in different signs is to be explored in our study as below.

\section{Methodology}

\subsection{The Definition of Ethnography}

Ethnography is designed to explore cultural phenomena where the researcher observes society from the point of view of the subject of the study, a means to represent graphically and in writing the culture of a group (Snow, 
Morrill, \& Anderson, 2003). Ethnography consists of the observation and analysis of human groups considered as individual entities, aiming at recording as accurately as possible the perspective modes of life of various groups (Claude Lévi-Strauss, 1963). As an approach of data collection, ethnography entails examining the behavior of the participants in a specific social situation and also understanding their interpretation of such behavior (Dewan, 2018). In accordance with these studies, our paper also follows the same approach looking at language practices at bottom level and revealing the bigger context of socioeconomic transformations between China and Vietnam.

\subsection{Data Collection and Description of Participants}

Data were collected by taking photos at public and private spaces and individual interviews were conducted to understand how local people learn various languages. The photos of linguistic landscapes collected at Hekou County are 93 in total, 50 of public signs and 43 of private signs, covering Hekou's typical places including government building, national border gate, hospital, commercial area, ethnic tourism area and Vietnam Town, etc.

For the interview, there are 16 participants taking part in the study and the questions are concerning their attitudes towards the values of different languages observed at Hekou County, their Vietnamese learning experiences and how their language backgrounds facilitate their life and work.

Our participants are local people living at Hekou and they are in different age from 18 to 25 with various ethnic backgrounds including Han, Yi, Yao and Zhuang. Most of them are receiving higher education or have graduated from university and work as civil servants. They are all able to speak Vietnamese with various proficiencies.

\subsection{Research Questions}

In order to understand how various languages have been used and practiced at Hekou, I have asked two research questions in the study:

(1) What are the language choices observed at Hekou County?

(2) What are the language ideologies embedded in these linguistic landscapes?

\section{Findings and Discussion}

\subsection{Language Choices Displayed in Hekou Linguistic Landscapes}

Many previous studies (Blommaert, 2013; Li, 2014; Shohamy \& Gorter, 2009) have divided the linguistic landscapes into public and private spaces. The following two tables categorize the distribution of language choices both from public and private signs.

Table 1. Distribution of different languages observed in public spaces

\begin{tabular}{lll}
\hline Language Ideologies & Language Choice & Public Signs \\
\hline Monolingualism & Chinese & gateway of nation; government building; road signs \\
Bilingualism & Chinese & Police Station; Hospital; Bank; Customs House \\
& English & \\
Chinese & Trade Fair; Official Notices; Hospital; Festival; Banners \\
& Vietnamese & \\
& Chinese & The Huashan Festival of Miao nationality \\
& Miao & \\
& Chinese & The Post Office \\
& Yi & \\
& Chinese & Road signs; Exhibition Room \\
& Zhuang & \\
& Chinese & Hospital notices; Station signs; Bank; Trade Fair; Road signs; Customs \\
& English & \\
Vietnamese & \\
\hline
\end{tabular}

Table 2. Distribution of different languages observed in private spaces

\begin{tabular}{ll}
\hline Language Choices & Private Signs \\
\hline Chinese & Shops; recruitment information; training center; LED screen; book store; recipe \\
Vietnamese & \\
Chinese & Food packaging; shop names; foreign currency exchange institution \\
English & \\
Vietnamese & \\
Vietnamese & Menu; food prices; shop names \\
\hline
\end{tabular}


Despite the fact that Hekou is a multilingual and multicultural centered border town, monolingual signs are observed in many public places such as national gate, government buildings and road signs. Chinese is the only language used in these public signs representing the national identity and political power. The following figure is the photo taken at the national border gate, just opposite Vietnamese border.

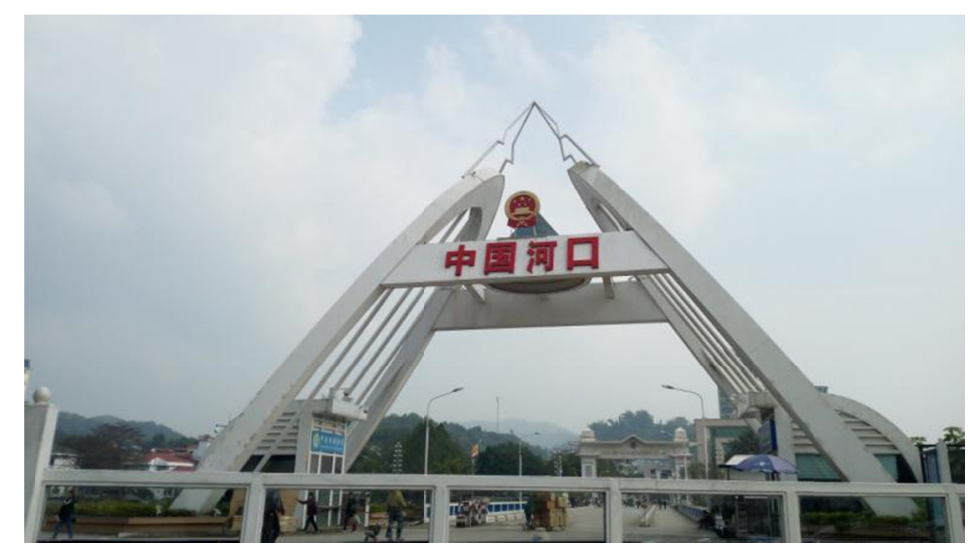

Figure 4. The monolingual Chinese sign for the name of "Hekou China" at the national gate

Besides monolingual signs, bilingual landscapes are observed with different patterns: Chinese and English, Chinese and Vietnamese, Chinese and minority language. These bilingual signs convey different social meanings in different contexts.

As a world lingua franca, English is a symbol of fashion and internationalization; even the remotest county can feel its impact. For one thing, using English can not only diversify language landscapes but also indicate how much a region is internationalized. English and Chinese are used in public places like Police Station, Railway Station and Hospital, Customs House, etc. With the improvement of infrastructure, there are more and more visitors coming to Hekou. At the Frontier Inspection Station, the official notices are written in Chinese and English, making the notices readable not only to local people but also to foreigners.

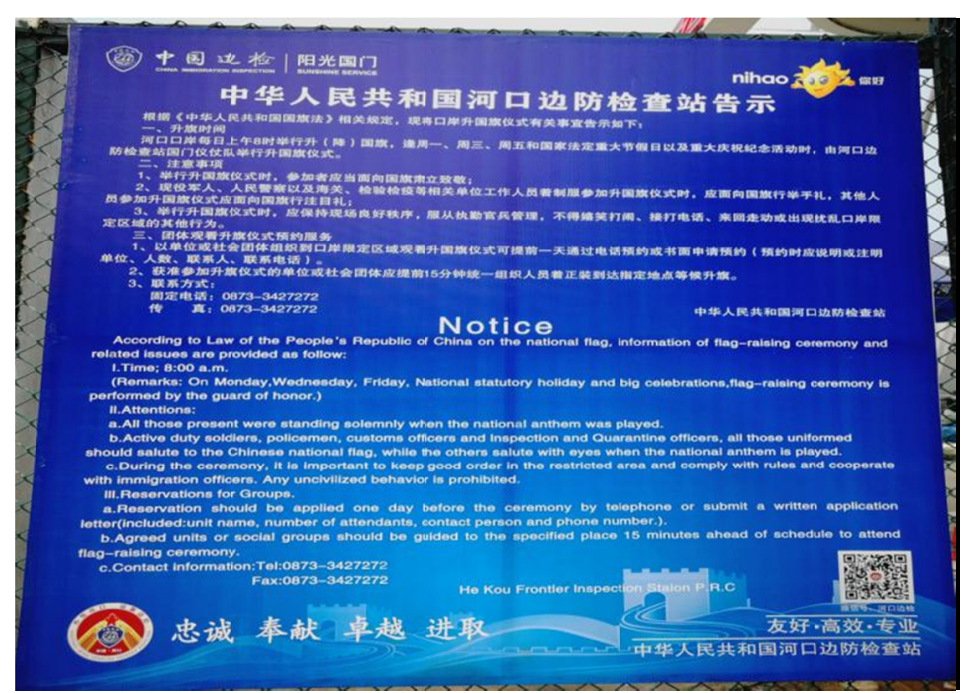

Figure 5. The bilingual Chinese and English sign in the inspection station notice

For bilingual Chinese and Vietnamese signs, they are about advocating socialist core values, regularizing behaviors, striking crimes and health publicity, aiming at educating local people as well as Vietnamese and reducing the difficulty of border management. Instability and unrest resulted from smuggling and drug trade is rampant in border regions, where literacy is lower and cross-border crime is hard to suppress ( $\mathrm{Li} \& \mathrm{Xu}, 2017$, p. 
85). At Hekou, notices written in Chinese and Vietnamese send the massages that border inhabitants in China and from Vietnam should both obey the law. These bilingual signs are for propagandizing for justice and maintaining stability and safety.

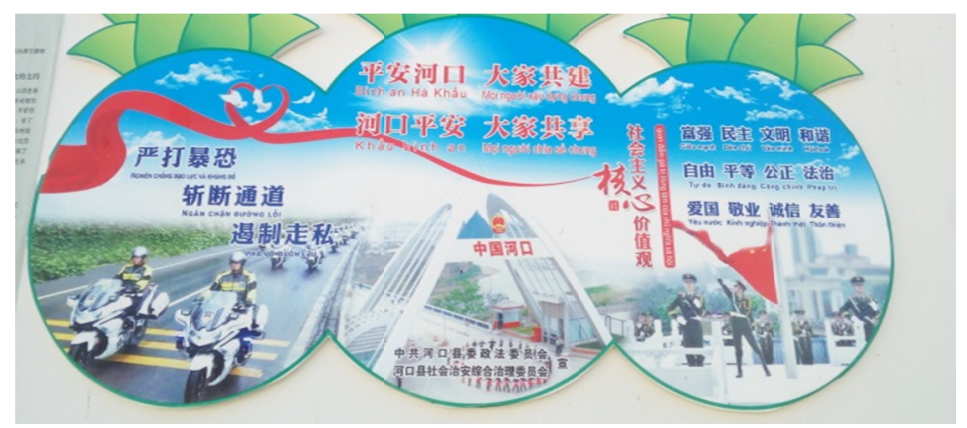

Figure 6. The bilingual Chinese and Vietnamese sign for promoting social justice

On some important cultural and social occasions such as the annual trade fair between China and Vietnam, banners and commodities written in Chinese and Vietnamese can be seen everywhere, showing respect and friendship for both countries. Moreover, in recent years, the number of Vietnamese migrants is rapidly increasing (Work Report of Human Resources and Social Security Bureau of Hekou County, 2017, p. 4), and as a result, in some hospital, sign board is presented in Chinese and Vietnamese for the convenience of Vietnamese workers at Hekou. On the one hand, the use of Vietnamese can provide those Vietnamese speakers with instant health care. On the other hand, more and more bilingual talents working in hospital are needed to facilitate the relationship between doctors and patients.

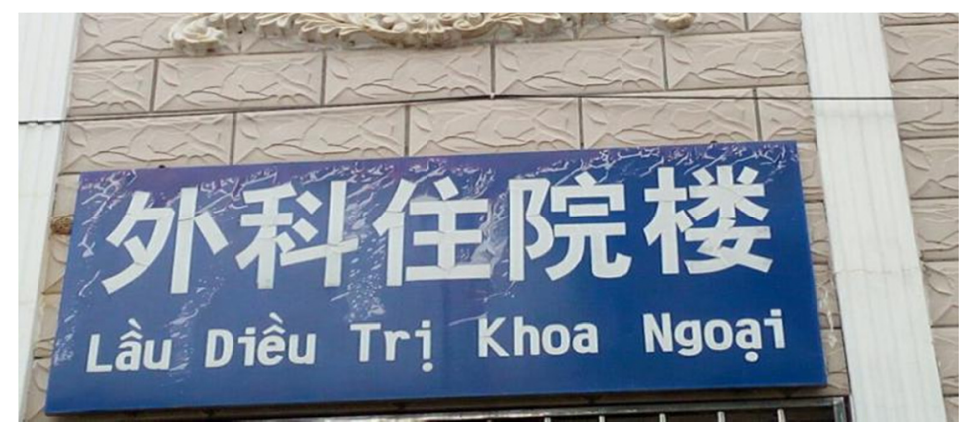

Figure 7. Bilingual Chinese and Vietnamese sign at the hospital

The bilingual patterns of Chinese and minority languages are often captured on cultural occasions. For example, on Huashan Festival of Miao ethnicity, banners are written in two types of bilingualism: Chinese and Miao or Chinese and Vietnamese. The use of Miao language can make the festival genuine and attractive. The use of Vietnamese on Chinese minority cultural activities can convey the meaning of border integration. Since there are many cross-border minorities living at China-and-Vietnam border-lines, the use of Vietnamese is a sign of welcoming people in Vietnam to attend this great festival and a successful example of promoting multicultural and multilingual diversity and border integration. Similarly, Zhuang language appears both at the road signs near Zhuang people's residential areas and at the exhibition rooms. At times of traditional festivals, visitors will come to see and experience the different lifestyle of Zhuang people. The exhibition room shows many aspects about Zhuang people, their costume, history and great ancestors. The use of Zhuang language combined with visual show will help to keep their heritage, protect traditional culture and, more importantly, to nurture future generation. Interestingly, Yi language appears only at the Post Office. One is the branch office of China Post, and the other is the old site Hekou Post Office. Through interviewing, it is known that the use of Yi language shows the accordance with Honghe Hani and Yi Autonomous Prefecture. The fact is that the state government uses Yi language as a way of preservation of cultural relics. 


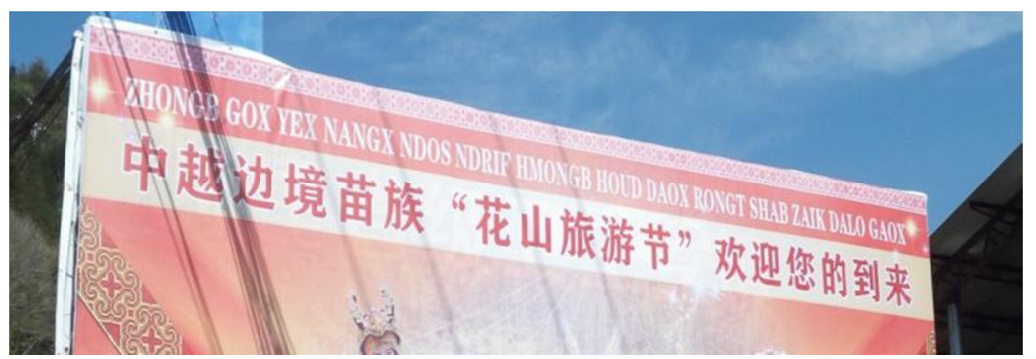

Figure 8. The bilingual Chinese and Miao sign

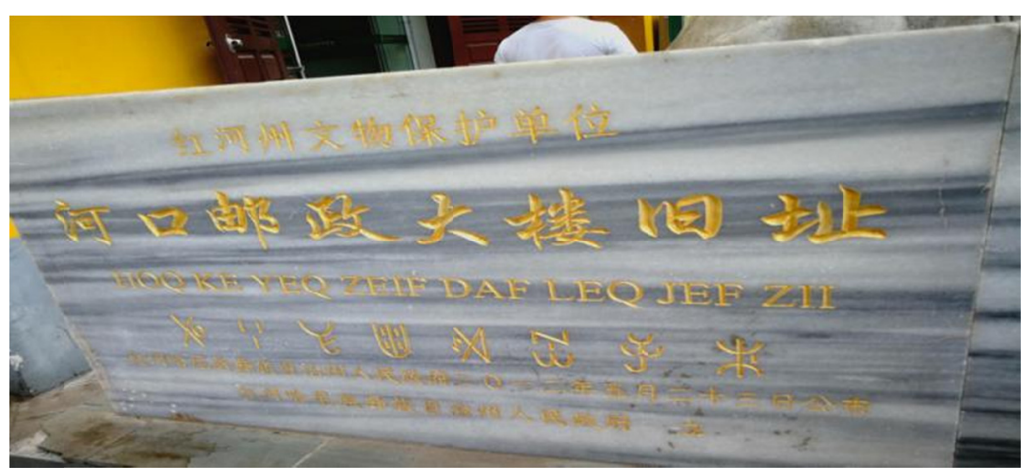

Figure 9. The bilingual Chinese and Yi sign at the site of post office

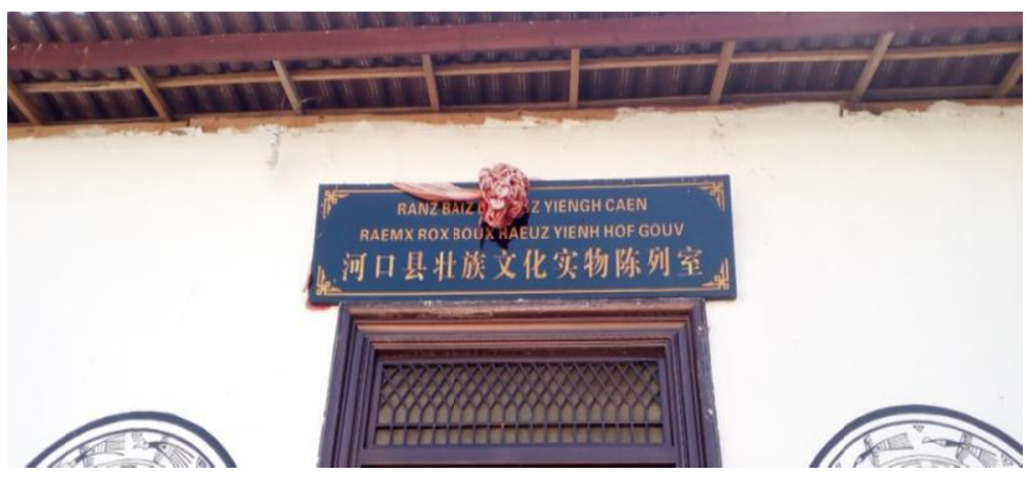

Figure 10. The bilingual Chinese and Zhuang sign

In contrast to public signs, Vietnamese is widely distributed into private space with various distribution patterns. In business places, Vietnamese often appears either alone, or with Chinese or with both Chinese and English. For monolingual Vietnamese, it is observed in Vietnam Town, a newly-built commercial district for Vietnamese businessmen doing redwood furniture, special products, restaurants, fruits and entertainment projects. In a similar way, monolingual Vietnamese is also observed from shop names and restaurant menus. Such visibility is associated with the increasing number of Vietnamese migrants in Hekou. Apart from serving Vietnamese migrants, using monolingual Vietnamese can contribute to the construction of Hekou as a tourist city where Chinese tourists may enjoy exotic Vietnamese culture and experience authentic food and local products. Thus, monolingual signs of Vietnamese serve for commercial and economic purposes. 


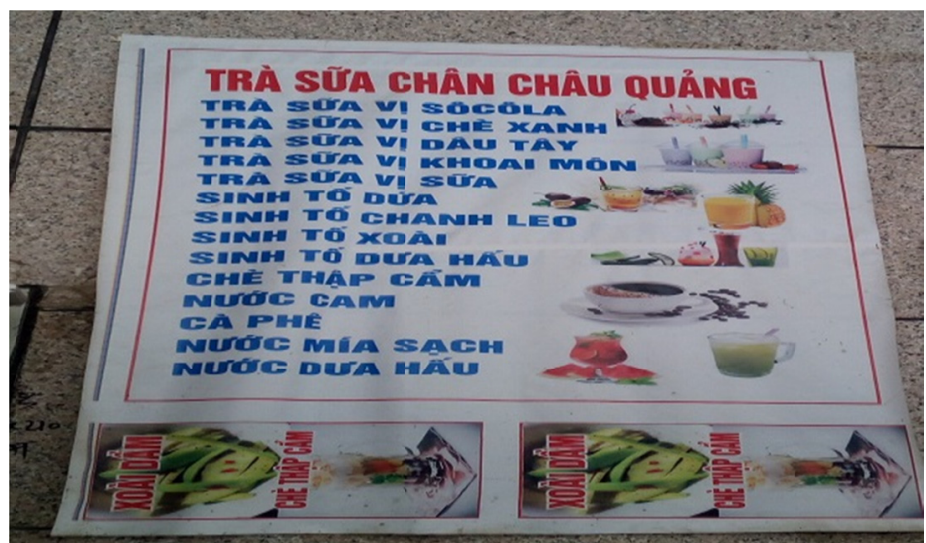

Figure 11. Monolingual Vietnamese sign at restaurant

Besides the promotion of Hekou's tourist image, the use of Vietnamese is also targeting Chinese people who need to learn Vietnamese for making businesses. This is particularly true to private entrepreneurs whose businesses are Vietnam-oriented. Timber industry and fruits market are often observed at the bilingual signs of Chinese and Vietnamese. These bilingual signs are serving those who lack Vietnamese proficiency but who want to import Vietnamese products and sell them in China.

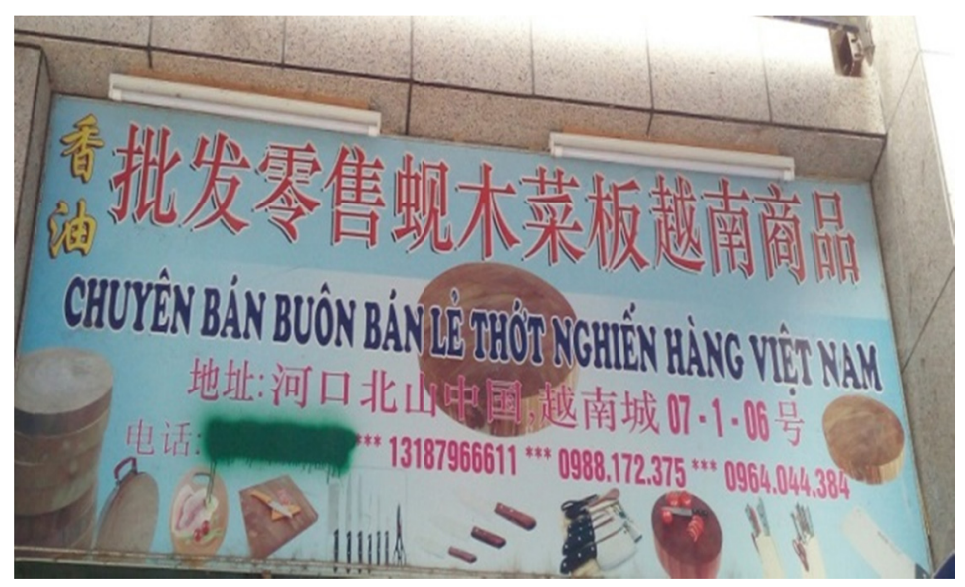

Figure 12. The bilingual signs by Vietnamese targeting at Chinese consumers

In addition, to purchasing Vietnamese products, more and more Chinese businessmen hope to speak good Vietnamese. By doing so, they can recruit cheap labor from Vietnam and save their cost and enter into Vietnam and purchase their products at a lower price. The following figure is one of the Vietnamese language training centers at Hekou.

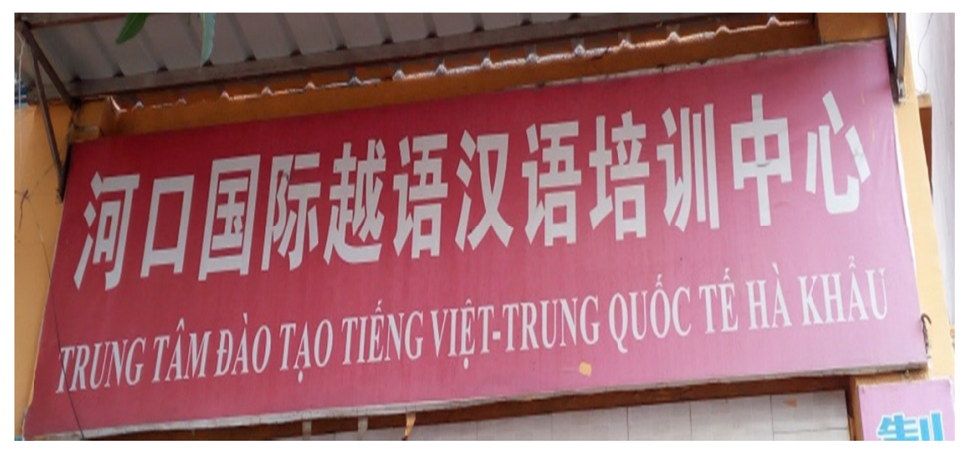

Figure 13. Bilingual signs at a training center 
In sum, various distributions of linguistic landscapes at Hekou indicate the border diversity and economic vitality between China and Vietnam. Because of the increasing bilateral cooperation and mutual interaction, the visibility of Vietnamese language can be spotted almost everywhere from hospital, government slogans to private shops and daily products. The need of speaking Vietnamese is also seen from Chinese people who are keen to explore the Vietnamese market and get close to Vietnamese migrants in China. The value of Vietnamese is becoming practical and market-oriented. Despite the fact that Hekou is a minority-centered border town, the local minority languages such as Miao and Zhuang only appear on cultural occasions and the use of minority languages seems to maintain the symbol of heritage identity rather than for the daily communication. Different from minority languages, English is spoken by nobody at Hekou but can be observed in many government institutions. This finding about the use of English as symbolic value is similar to Li's (2017) study at China-and-Myanmar border where English is also found in many public signs even though local people do not use it for daily communication. In spite of its peripheral location, Hekou as China's border town represents the image of China and the use of Chinese often takes the highest status of linguistic hierarchy at the multicultural and multilingual-centered border town. In accordance with the national strategic positioning, monolingual Chinese signs are exclusively found at public space where national boundary is clearly marked by linguistic sign.

\subsection{One More Language, One More Way Out}

At Hekou, multilingual practices can be observed both in public and private spaces as indicated in the study of linguistic landscapes above. The following section aims to reveal how language benefits my participants' future and settlement experiences at the border town in one way or another. The discussion is categorized by my participants' linguistic repertoires: monolingual Chinese speakers, bilingual speakers of Chinese and minority language, and multilingual speakers of Chinese, Vietnamese and other language(s).

As the official language in China, Chinese language indicates the speakers' identities and social status at Hekou. Despite Hekou's linguistic diversity, Chinese enjoys the most visibility and is widely used in government institutions. Those whose mother tongue is not Chinese have to make efforts to learn to speak standard Putonghua and to write Chinese words in order to secure their academic success and job position. However, only speaking Chinese at Hekou is not sufficient for local communication and future profit given that the majority of local residents and border migrants do not speak Chinese as their mother tongue.

In fact, speaking both minority language and Chinese can gain many advantages at study and job recruitment. In local recruitment examinations, many posts are reserved for minority candidates who can speak Chinese and their minority language. Because of his bilingual talents in Yao and Chinese, participant Deng has successfully passed the public institution examination in 2016 and now works for the local government. The probability of employment success is higher for minority candidates. As an autonomous and multinational county, Hekou needs bilingual or trilingual speakers of Chinese and other minority languages who can report to the government what minority people want and who can promote government policy to the people. The effective communication between government and people is indispensable in maintaining social stability, economic prosperity and minority integrity. Therefore, those who are specialized in both Chinese and minority language become the ideal talents. Besides, the preference for bilingual speakers is increasingly needed and this is associated with the promotion of local tourism. In order to improve the local economy and the image of border harmony, Hekou is constructing itself as a tourism-centered border town. There is an urgent need for both Chinese and minority speakers especially on cultural occasions like Huashan Festival of Miao ethnicity and Hua Mifan Festival of Zhuang ethnicity. People who are capable of speaking Chinese and minority languages will be first selected to cater to visitors and government officials.

Different from the bilingual speakers of Chinese and minority language, those who can speak Chinese and Vietnamese seem to find more profitable opportunities for their academic and employment trajectories in recent years. Take Chen for an example, seeing the profitable future of speaking Vietnamese, Chen chose to study at a Vietnamese university after graduating from his high school. Compared to those who have to compete for Gaokao (the national university entrance exam in China), Chen easily succeeded in enrolling at one of the distinguished universities in Vietnam. Compared to those who dream of doing overseas studies in English speaking countries, Chen finds it affordable to study at Vietnam and it only costs Chen 15,000 yuan a year covering all of the expenditure at school. Because of his Vietnamese proficiency, Chen has been granted with a good job working at the government department in 2017. Similar to Chen, Zhang has also secured her job for the local government after graduating from a Chinese university majoring in Vietnamese. In fact, at Hekou, bilingual speakers of Chinese and Vietnamese are urgently needed. In 2018, there are three institutions recruiting people majoring in Vietnamese: The Management Council of Hekou Cross-border Economic Cooperation Zone, Transport Agency and Foreign Affairs Office (Bureau of Human Resources and Social Security of Honghe 
Prefecture, 2018). As China' and Vietnam' cooperation expands, bilingual or multilingual speakers of Chinese and Vietnamese and other languages will find a foothold both in private and in government institutions.

In sum, at Hekou, speaking good Chinese is a must for academic success and job position, but still it is not sufficient for individual development because of Hekou's multilingual practices. Bilingual speakers of Chinese and minority languages are needed to bridge the communication between the government and minority people who are namely, the majority of local residents. Bilinguals of Chinese and minority languages are also needed in promoting local tourism and border harmony. For those capable of speaking Chinese and Vietnamese, they are endowed with more profitable opportunities both in academic and employment trajectories. Linguistic competence in both Chinese and Vietnamese can provide local residents with an easy access to doing studies in Vietnam without costing much money and without competing with their Chinese peers for Gaokao. What's more, having a degree obtained from Vietnam means having a decent job both in private and in government institutions.

\subsection{Newly Emerged Forms of Elite Bilingualism}

Since the establishment of China-ASEAN Free Trade Area, the demand for foreign language talents is more urgent than ever before. Being positioned as one of the important forefront border towns, Hekou port has been taking the advantage of its geography and reinforcing cooperation with Vietnam. For individuals, being bilingual in Chinese and Vietnamese is greatly beneficial in many aspects.

Regarding those learning Vietnamese at school, they find that their language learning experiences have helped them establish cross-cultural friendship and they all find it easier to learn Vietnamese than English. In the interview, Pan points out that "if you are good at Vietnamese, you will be chosen to be student representative to Vietnam for exchange programmes and you will get to know more Vietnamese friends". Besides, Vietnamese competence enables you to do business with those from western and southern Vietnam. Deng states that in high school, he was chosen to be a translator for the student soccer competition between China and Vietnam. His Vietnamese language translating experiences help him make new friends and establish interpersonal relationship. In fact, similar cultural and linguistic exchange programmes are quite intense, and Hekou Senior High School even offers Vietnamese class once a week for the purpose of laying a foundation for students' foreign language competence and promoting the mutual educational cooperation between China and Vietnam. But when it comes to English learning, most participants point out that they are not capable of speaking good English even though they have received English formal education at school for over ten years. At Hekou, there is the lack of English learning resources such as English native speakers and qualified teachers. In contrast, Hekou is famous for its Vietnamese learning resources. Whenever my participants go up the street, they can easily spot the visibility of Vietnamese language listed on various landscapes and it is also convenient for them to approach Vietnamese speakers who are doing business at Hekou.

At Hekou, learning Vietnamese at high school is not only for the purpose of passing a subject test, but more importantly for the preparation of students' future trajectories. Graduating from high school education, students can choose to study at Vietnam universities or major in Vietnamese at Chinese universities just like Chen and Zhang's stories above. In terms of work, being able to speak Chinese and Vietnamese will be much favored. Majoring in Vietnamese, Chen and Zhang stand for two different groups of students. Chen graduated from Vietnam universities. His experiences as exchange student to Vietnam helped him better understand Vietnamese culture, got him closer to local life style and made him familiar with Vietnamese commercial customs. These overseas learning experiences helped him secure a good job later in the government. Zhang, on the other hand, represents those students major in Vietnamese at Chinese universities. She did have less time spent studying in Vietnam, but her Vietnamese major made her the colleague of Chen. She took the urgently-needed personnel examination of Hekou County and was admitted by the Bureau of Human Resources and Social Security. English, however, does not seem to have the potential of securing a bright future. Just as Zhang describes:

"Hekou borders northern Vietnam where the popularization rate and applicability of English are lower than that of Vietnamese. Even if someone can learn English well, they will not necessarily find a good job at Hekou especially at a time when the training scale of English students has reached saturation".

It is reported that there is the surplus of English talents and the waste of educational resources (Cheng, 2013, p. 101). In fact, none of the schools at Hekou hires English teachers in this year's public institution examination and this speaks something about the uselessness of English at such a Vietnamese-centered border town. In contrast, bilingual speakers of Chinese and Vietnamese are needed at Hekou in many fields like China-Vietnam commercial trade, translation and reception, company management and tourism management, etc.

Apart from learning Vietnamese through formal education at schools of various levels, Vietnamese is also 
widely taught at many private training centers targeting at those who are doing Vietnam-oriented businesses and some local people even cross the border to invest on learning Vietnamese language. Luo has been doing business with Vietnamese after his high school education. Inspired by Vietnamese teaching in high school, he has seen this great commercial value attached to Vietnamese and then signed up for training courses and started his business. Besides the rich language learning resources at Hekou, many border migrants can afford to learn Vietnamese language in Vietnam. Bao, now a freshman at Hanoi University, describes that there are many Chinese people of different ages going to Hanoi University for studying Vietnamese either for short or long term. As Chen says, "China's development is very rapid. You cannot wait for Vietnamese people to learn Chinese language". People at Hekou seize the great opportunity of China-Vietnam economic cooperation and get themselves actively involved in national development strategy by learning Vietnamese language at various types of schools and training centers.

The increasing value of speaking Vietnamese language is not only seen at government, education and business sectors but also witnessed among border people who share the same kinship ties. Yunnan Province borders Vietnam, Laos and Myanmar with a boundary line of 4060 kilometers (Tang, Qian, \& Yang, 2017, p. 1082). On both sides of the border line, there live 16 transnational nationalities such as Zhuang, Dai, Miao, Yao, Hani and Jingpo (Li, 2016, p. 86). Though separated by state lines, border people's languages and customs are still connected for generations. At Hekou, the cross-border visit and cross-border marriage are not uncommon. People living on both sides of the border are actually relatives and friends. One of my participants Hou states that learning to speak Vietnamese makes her feel more intimate to know her relatives living on the opposite side of the border.

In sum, the values of learning Vietnamese have been widely acknowledged by people of all walks of life. For one thing, people at Hekou can easily get access to rich Vietnamese learning resources. For another, Vietnamese language carries the power of making profit in the border trade. People learn it through various types of schools and private training centers and they even go to Vietnam for more efficient study. Being a proficient speaker of Vietnamese is valuable for working in the government institutions, school education and business sectors. Furthermore, speaking good Vietnamese is also useful in promoting mutual communication in border visit and marriage and keeping border integrity.

\subsection{Revitalization of Minority Languages}

Many previous studies in sociolinguistics state that minority languages are disappearing in China and many other countries (Wang \& Zhou, 2014, p. 171). However, this does not seem to be the same case at the peripheral border town between China and Vietnam.

At Hekou, there is an increasing visibility of Miao, Zhuang and Yi languages displayed in different linguistic landscapes. Most of these minority languages appear on cultural festivals. For example, on Huashan Festival, both Miao language and Miao people's cultural activities have been promoted. Zhuang language is seen at Zhuang nationality's community on road signs and cultural displaying rooms especially on Hua Mifan Festival. Such increasing visibility of minority languages at Hekou is a sign of revitalization of minority languages under the driving force of promoting ethnic tourism. As a minority-centered autonomous county, Hekou local government undertakes an active duty to seize the great opportunity to develop ethnic cultural tourism. For one thing, minority diversity is a new economic growth point and ethnic culture is attractive to visitors, which can accelerate local tourism development. For another, ethnic tourism will help to protect endangered minority languages and traditional culture. Every year, there are various kinds of minority festivals held at Hekou County, making much contribution to local economic growth.

Besides the promotion of local tourism, the revitalization of minority languages at Hekou is also associated with the construction of the border harmony and border peace. In Qiaotou Country only, there are about 300 hundred to 600 hundred of Vietnamese coming to attend Chinese Huashan Festival (Tang, Qian, \& Yang, 2017). Qiaotou is in the northeast of Hekou and 78 kilometers away from it. Due to the shared cultural practices and kinship ties on both sides of China-and-Vietnam border, the highly promoted minority language plays an important role to integrate the border diversity and to create the border peace between two countries. As a result, the increasing visibility of minority languages not only brings economic profit to the local government, but also provides an image of peaceful border development for China's and Vietnam's mutual cooperation, in particular for China's Belt and Road Initiative to its neighboring countries.

Despite its peripheral location, Hekou plays an essential role linking China to Vietnam and other Southeast Asian countries. Because of this strategic positioning, speaking Vietnamese becomes a newly emerged capital at the border town of Hekou. The values of being bilingual in Chinese and Vietnamese have been widely 
recognized both in private and public sectors. Chinese students who used to struggle in learning English are now aware of the emerging values of speaking Vietnam and doing advanced education in Vietnam. Learning Vietnamese at China's peripheral region like Hekou not only provides border students with an easy access to language learning resources but also builds up a different future trajectory from that of their peers studying at China's hinterland. As a minority-centered and Vietnamese-oriented border town, Hekou is in great demand of multilinguals for local tourism, border integrity and China's expanding cooperation with its neighboring countries. Bilingual speakers of Chinese and minority languages are helpful both in communicating between government and local people and in keeping the prosperity of local tourism and border peace between China and Vietnam.

\section{Conclusion}

The fact that multilingual practices can be spotted both in public and private spaces is the manifestation of cultural and language diversity. Chinese is the most widely used language even at such a remote border town given its status as China's official and national language. It is an essential language for individual development in academic and job success. English, as a world lingua franca, is observed at Hekou in some public places such as hospital and railway station. Its wide use stands for the degree of internationalization and openness of Hekou County. The fact that minority language acquires symbolic function rather than pragmatic function is related to the promotion of local ethnic tourism. Minority languages carry the value of cultural resources and it is used as tourism products and the use of minority language is the result of tourism prosperity and government's language protection. In contrast, Vietnamese, as a newly emerged language capital at Hekou, is being more and more popular. People at Hekou make active efforts in learning Vietnamese and seize the great opportunity of China-Vietnam cooperation by attending school education and signing up for various types of Vietnamese training centers. Language use of Vietnamese speaks for the ongoing cooperation between China and Vietnam and China's cooperation with ASEAN, especially its neighboring countries like Vietnam.

Because of Hekou's local development needs, bilinguals of Chinese and Vietnamese or Chinese and minority languages are having more profitable opportunities than those bilinguals of English and Chinese in getting a decent job both in the government and private institutions. As an important border town linking China with Vietnam and other Southeast Asian countries, Hekou is taking advantage of its strategic positioning to develop its foreign trade arising from a peripheral border town to a strategically important trading node. Language talents in Vietnamese and Chinese are needed in various levels of political, economic, cultural and educational communications between China and Vietnam, making their life trajectories different from and brighter than those majored in English. Furthermore, as a minority-centered border town, language talents in both Chinese and minority languages are indispensable in communicating between the government and minority people. Besides the need of government administration, bilingual speakers of Chinese and minority languages are also needed in promoting ethnic tourism and minority integrity. Hekou is working to achieve the benefits of multilingual practices in promoting economic prosperity, political stability and border integrity, to realize the function of social service of language especially at a time when China is expanding cooperation with Southeast Asian countries.

The study has shed some lights on the language practices and social reality at Hekou and it can provide some practical guidance on language policy for the border development. Due to the fact that the study is only based on a small border town and the number of the participants is also limited to what the author can have access, it is therefore suggested that future work should be conducted on a more comprehensive and even a longitudinal basis in order to understand the dynamic change of language use and the social practices.

\section{Acknowledgements}

This study was supported by Yunnan University under the Grant [No.18YNUGSP015]; [2019077] and funded by the College of Foreign Languages of Yunnan University under the Grant [C176210301].

\section{References}

Backhaus, P. (2005). Signs of Multilingualism in Tokyo: A Linguistic Landscape Approach. PhD thesis, University of Duisburg-Essen. https://doi.org/10.21832/9781853599170-004

Bai, Y. (2016). The study of impacts on Hekou border trade and the construction of new urbanization. Silkway Vision, 1-2.

Blommaert, J. (2013). Ethnography, Superdiversity and Linguistic Landscapes: Chronicles of Complexity. Bristol: Multilingual Matters. https://doi.org/10.21832/9781783090419
Burea
of
Honghe
Human
Resources
and Social Security.
(2018).
Retrieved
from 
https://www.hhzrc.cn/Article/Index/Index/show/id/4902

Claude, L.-S. (1963). Structural Anthropology. New York: BASIC BOOKS, INC., Publishers.

Cheng, H. (2013). On the importance and necessity of developing less commonly taught foreign language programs in the context of globalization: a case study based on Vietnamese language program. Journal of Honghe College, 11(05), 101-105.

Dewan, M. (2018). Understanding Ethnography: An 'Exotic' Ethnographer's Perspective. In P. Mura \& C. Khoo-Lattimore (Eds.), Asian Qualitative Research in Tourism. Perspectives on Asian Tourism. Springer, Singapore. https://doi.org/10.1007/978-981-10-7491-2_10

He, Z., \& Hao, J. (2014). The study of trade between China and Vietnam (2003-2013). Around Southeast Asia, 9 , $58-62$.

Hekou Year Book Editorial Department. (2016). The Annual Chronicle of Hekou Yao-Municiple County, 513515.

Heller, M. (2006). Linguistic Minorities and Modernity: A Sociolinguistic Ethnography (2nd ed.). London: Continuum.

Huebner, T. (2006). Bangkok's linguistic landscapes: environmental print, codemixing and language change. In D. Gorter (Ed.), Linguistic Landscape: A New Approach to Multilingualism (pp. 31-52). Clevendon: Multilingual Matters. https://doi.org/10.21832/9781853599170-003

Li, D. (2016). On constructing the regional language Service in the context of Belt and Road: a case study of Yunnan. Journal of Bohai University (Philosophy and Social Science Version), 38(01), 85-89.

Li. J. (2014). Cross-border Linguistic Landscapes between China and Myanmar. AILA World Congress, Brisbane, Australia.

Li, J. (2017). Social Reproduction and Migrant Education: A Critical Sociolinguistic Ethnography of Burmese Students at a China's Border High School. PhD Dissertation, Sydney: Macquarie University.

Li, Q., \& Xu, M. (2017). The challenge and strategies of controlling the crime of smuggling along the borderland of Yunnan. The Journal of Police Institute, 6, 85-86.

Liu, Y., \& Li, T. (2009). On the Folklore of Honghe (pp. 19-24). Yunnan: Yunnan People's Press.

Lou, J. (2016). The Linguistic Landscapes of Chinatown: A Sociolinguistic Ethnography. Bristol: Multilingual Matters. https://doi.org/10.21832/9781783095636

Mo, Z., \& Yang, R. (2016). The Social Impacts of Sino-Vietnamese relationship on the education of Vietnamese language at Chinese universities: a case study based on the universities of Dian, Gui and Chuan provinces. College Education, 2,71-74, 77.

Ou, M., \& He, M. (2016). The effect, problem and suggestion on the border construction in Yunnan and Guangxi. Asian-Pacific Economy, 1,123-127.

Qin, H. (2017). The analysis of developing the urbanized border town between China and Vietnam. The Journal of Yunnan Normal University (Philosophy and Social Science Version), 49(03), 47-54.

Shang, G., \& Zhao, S. (2014a). The perspective, theory and method for studying linguistic landscapes. Foreign Language Teaching and Research, 46(02), 214-223, 320.

Shang, G., \& Zhao, S. (2014b). The analysis of domansion and theoretical construction for linguistic landscapes. Foreign Languages, 37(06), 81-89.

Shohamy, E., \& Gorter, D. (eds) (2009). Linguistic Landscape: Expanding the Scenery. London: Routledge. https://doi.org/10.4324/9780203930960

Snow, D. A., Morrill, C., \& Anderson L. (2003). Elaborating analytic ethnography: Linking fieldwork and theory. London, Thousand Oaks.

Tang,X., Qian, J., \& Yang, X. (2017). The cultural and ethnic identification from the perspective of mobility : a case study of Huashan festival of Miao ethnicity at the China-and-Vietnam border. Geographic Science Development, 36(09), 1081-1091.

Wang, J., \& Zhou, X. (2014). On language disappearance and ethnic identification. Guizhou Ethnicity Study, $35(01), 169-172$.

Yang, J. (2017). The recent development, existing problem and corresponding solutions for developing the 
Sino-Vietnam economy and trade. Contemporary Economics, 35, 12-13.

Yang, L. (2014). The analysis of economic advantages of border economy and industrial planning along the borderland between China and Vietnam. Economy Study and Reference, 5, 32-35.

Zeng, R., \& Liu, Z. (2005). The analysis of the state of the art on developing Vietnamese language for Guangxi. Around Southeast Asia, 11, 76-79.

\section{Copyrights}

Copyright for this article is retained by the author, with first publication rights granted to the journal.

This is an open-access article distributed under the terms and conditions of the Creative Commons Attribution license (http://creativecommons.org/licenses/by/4.0/). 